\title{
Combining Two Individualized Lung Recruitment Maneuvers at Birth for Very Preterm Infants: a Retrospective Cohort Study
}

Zalfa Kanaan (MD) ${ }^{1}$, Marouane Boubaya ${ }^{2}$, Coralie Bloch-Queyrat (MD, PhD) ${ }^{2}$, Vincent Lévy (MD, PhD) ${ }^{2}$, Pascal Bolot (MD) ${ }^{1}$, Paul Waszak (MD, PhD) ${ }^{1}$

1 Service de Réanimation Néonatale et Néonatalogie, Hôpital Delafontaine - Saint-Denis, France

2 Unité de Recherche Clinique, Groupe Hospitalier Paris Seine Saint-Denis, APHP, Bobigny, France

\section{Introduction}

Current international guidelines recommend starting resuscitation of premature infants with:

an intermittent positive pressure ventilation (PPV),

using a PEEP of 5-6 $\mathrm{cmH} 2 \mathrm{O}$ with

the first insufflations of 2-3 $\mathrm{s}$ (but not greater than $5 \mathrm{~s}$ )

However, these measures are probably not sufficient for recruiting the optimal functional residual capacity (FRC).

Current knowledge on the respiratory transition at birth:

- Phase 1 (30 sec to $5 \mathrm{~min}$ ): fetal lung fluid is evacuated. Sustained inflation (SI) aerates homogeneously the fluid-filled lungs.

- Phase 2 (up to $4 \mathrm{~h}$ ): accumulation of fluid in the interstitial space. Adequate PEEP helps to maintain the fluid in the interstitial tissue..

- Phase 3: Aerated lungs

(Hooper et al. ADC Fetal \& NN Ed. 2016;101:F266)

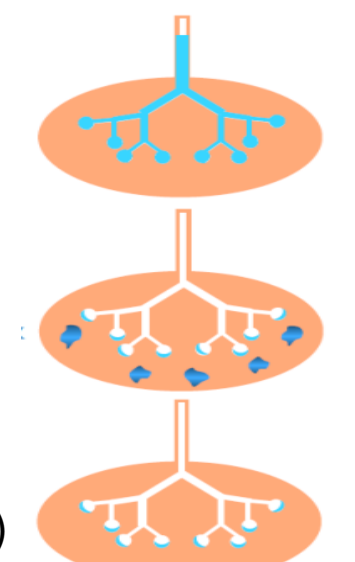

Lung recruitment (LR) maneuvers at birth using SI were assessed in randomized controlled trials with promising but also limited results (Schmölzer et al. ADC Fetal \& NN Ed. 2015;100:F361).

The dynamic PEEP strategy, assessed in animal models, is another maneuver able to establish an optimal FRC, as would an

SI strategy optimized by Electrical Impedance

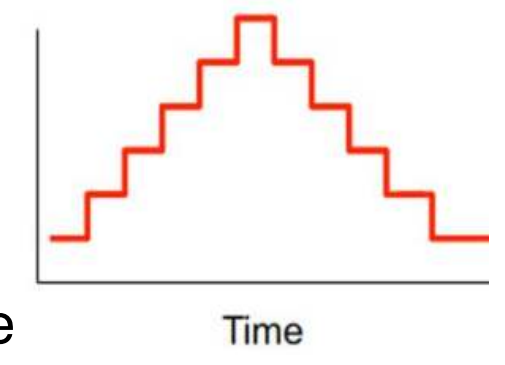

Tomography (Tingay et al. AJP Lung Cell Mol Physiol. 2017;312:L32).

As nobody knows what the optimal SI durations and PEEP levels are, we hypothesized that very preterm infants (VPIs) $<32$ weeks require an individualized LR combining both maneuvers.

\section{Objective}

To evaluate whether combining two individualized LR maneuvers (SI and dynamic PEEP) at birth is superior to current international guidelines.

\section{Methods}

In this retrospective cohort study, 100 and 102 inborn VPI were enrolled between 2014 and 2016, before and after introducing

\section{LR maneuvers.}

Inclusion criteria: Inborn VPI $<32$ weeks, need for pulmonary resuscitation.

Exclusion criteria: associated congenital malformations. Intervention: progressive increase in SI and PEEP (every 1 or 2 $\mathrm{SI}$ ) in case of apnea and/or $\mathrm{HR}<100 / \mathrm{min}$ and/or $\mathrm{FiO}_{2}>0.4$ :

\section{SI: 3 to 5 to 10 to 15 seconds}

PEEP: 5 to 8 to 10 to 12 to $15 \mathrm{cmH} 2 \mathrm{O}$

Sls were stopped when spontaneous breathing was observed, while a gradual decrease in PEEP was performed at an $\mathrm{FiO}_{2}<0.4$

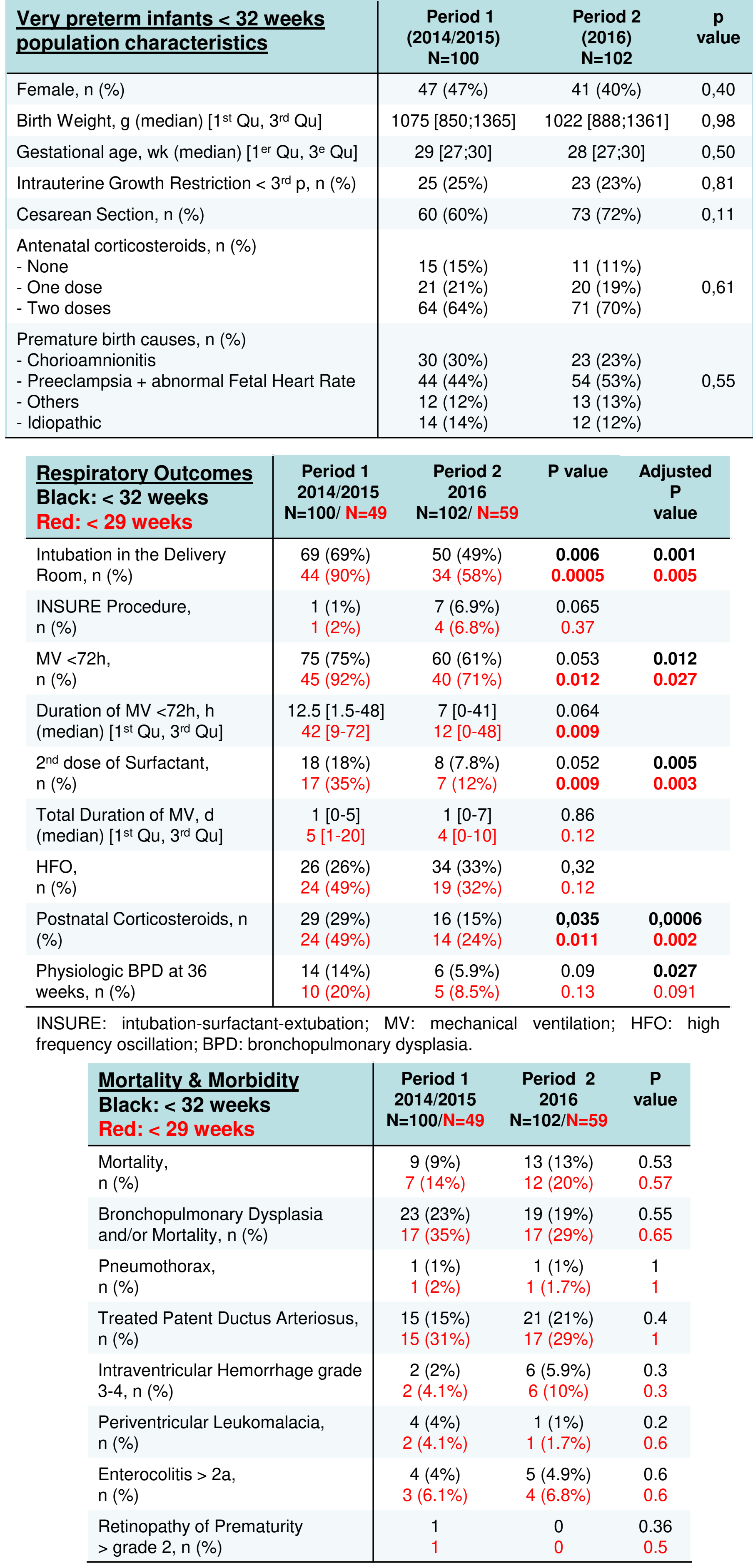

\section{Conclusion}

In our setting, combining two individualized LR manoeuvers at birth showed significant benefits, on short- and mid-term pulmonary outcomes without increasing morbidity or mortality. These results may open the door to a randomized controlled trial. 